Journal of Applied Pharmaceutical Science Vol. 5 (08), pp. 082-089, August, 2015

Available online at http://www.japsonline.com

DOI: $10.7324 /$ JAPS.2015.50813

ISSN 2231-3354 (cc) BY-NC-SA

\title{
Adansonia digitata leaf extract mediated synthesis of silver nanoparticles; characterization and antimicrobial studies
}

\author{
Chennareddy Maruti Kesava Kumar, Pulicherla Yugandhar*, Nataru Savithramma \\ Dept. of Botany, Sri Venkateswara University, Tirupati-517502, Andhra Pradesh, India.
}

\section{ARTICLE INFO}

Article history:

Received on: 07/05/2015

Revised on: 24/05/2015

Accepted on: 13/06/2015

Available online: 28/08/2015

Key words:

Adansonia digitata, Silver

nanoparticles,

Characterization,

Antimicrobial activity.

\begin{abstract}
Objectives: In the present study we report a simple, eco-friendly and cost effective method for synthesis of silver nanoparticles (SNPs) from Adansonia digitata leaf extract and perform to know the antimicrobial potency on 07 bacterial and 05 fungal pathogens.

Materials and Method: These green synthesized nanoparticles are characterized by UV-VIS spectroscopy, FTIR, XRD, AFM, SEM, TEM and to know the antimicrobial potency of nanoparticles by disc diffusion method. Results and Discussion: A broad peak obtained at $431 \mathrm{~nm}$ of UV-VIS spectroscopic analysis confirms the synthesized nanoparticles are silver. Phenols and proteins of leaf extract is main responsible for reduction and stabilization of these nanoparticles confirmed by FTIR. XRD pattern of synthesized nanoparticles confirms the particles are crystalline in nature and owing $44 \mathrm{~nm}$ in size. EDAX analysis shows 34.22 weight percentage of $\mathrm{Ag}$ material in the reaction medium indicates purity of sample. High resolution microscopic studies with AFM, SEM and TEM analysis reveals the nanoparticles are polydispersed in condition, spherical in shape, having the size range from 5 to $64 \mathrm{~nm}$ without any agglomeration. Further, the antimicrobial studies confirm the nanoparticles having broad range of antimicrobial efficacy against clinically isolated pathogenic microorganisms.

Conclusions: SNPs synthesized by using Adansonia digitata leaf extract acts as effective reducing agent for production of narrow range size of SNPs. This method provides pave a way for green, cost effective and ecofriendly method for production of SNPs and can be used as effective antimicrobial agents on clinically isolated microbial pathogens.
\end{abstract}

\section{INTRODUCTION}

Synthesis of nanoparticles by using plant extracts with desired size and shape is one of the utmost emerging fields of nanotechnology. Recently different types of nanoparticles were synthesized from different plants like iron (Herrera-Becerra et al., 2008), copper (Lee et al., 2013), calcium (Yugandhar and Savithramma, 2013), gold (Veronica et al., 2014), zinc (Bhumi and Savithramma, 2014) and silver (Yugandhar and Savithramma, 2015). Silver has long been known to have strong inhibitory and bactericidal effects as well as broad spectrum of antimicrobial activities even at low concentrations (Morones et al., 2005). Silver has recognized importance in chemistry, physics and biology due to its unique properties. Conventional methods to synthesize silver nanoparticles are mainly by different chemical, physical and microbial approaches.

* Corresponding Author

Pulicherla Yugandhar,

Email: yugandharbotany@gmail.com
In these chemical and physical methods using of hazardous chemicals, high energy requirements, difficult and wasteful materials generate potential and biological hazards to the environment (Veerasamy et al., 2011). Whereas in the case of microbe mediated synthesis, is not feasible industrially due its lab maintenance. Therefore biosynthesis of SNPs by using plant materials is easy, efficient, and eco friendliness in comparison to chemical mediated or microbe mediated synthesis (Anamika et al., 2012). Adansonia digitata L. (Baobab) is a deciduous tree belongs to the family Malvaceae having unusual barrel-like trunks. Traditionally the root bark is used in the treatment of fever (Wickens, 2008). The gum obtained from stem bark is used for cleansing sores. In East Africa, the bark is used as an antidote to Strophanthus poisoning. In Congo Brazzaville, the bark decoction is used to bathe rickety children and in Tanzania as a mouthwash for toothache (Wickens, 1979). The leaves, bark and fruit pulp have been traditionally used as immune stimulants, analgesics etc. and in the treatment of diseases like fever, diarrhoea, cough, dysentery, haemoptysis, tuberculosis, microbial infection and 
intestinal worms (Vermaak et al., 2011). The fruit pulp used as an immune stimulant, anti-inflammatory, analgesic, antipyretic, febrifuge and astringent in the treatment of diarrhoea and dysentery (Qarawi et al., 2003). Seeds are used in cases of diarrhoea and hiccough. Oil extracted from seeds is used for inflamed gums and to ease diseased teeth and also used to treat skin complaints, it can be considered to have cosmetic applications as well (Sibibe and Williams, 2002).

In the recent past some of the researches scientifically proved that methanolic root extract having antiviral activity (Sulaiman et al., 2011), leaves possess larvicidal and repellent activity (Krishnappa et al., 2012), antimicrobial and antioxidant activities (Oloyede et al., 2010), stem bark having hypoglycaemic activity (Gwarzo and Bako, 2013) and fruit pulp having antimalarial activity (Musila et al., 2013). Due to high medicinal and mythological significance of this plant is known as 'Kalpavriksha' (tree which fulfil all desires) in India (Singh et al., 2013).

Synthesis of SNPs from stem bark extract of $A$. digitata was carried out by Marutikasavakumar et al., (2015). But the potentiality of leaves for synthesis of SNPs is not carried out so far. Hence the present study is aimed to synthesize the SNPs from leaf extract of $A$. digitata and test the efficacy of these SNPs on clinically isolated pathogenic microbes.

\section{MATERIALS AND METHODS}

\section{Plant collection and Synthesis of SNPs}

A. digitata fresh leaves were collected from Acharya Nagarjuna Agricultural University, Tirupati. $25 \mathrm{gms}$ of finely grounded leaf powder is extracted with $100 \mathrm{ml}$ of distilled water on boiling water bath for 20-30 min. Filter the content with whatman no. 1 filter paper and stored it on room temperature for synthesis of SNPs. $5 \mathrm{ml}$ of filtered plant leaf extract was taken in to clean $250 \mathrm{ml}$ Erlenmeyer conical flask, titrated against with 50 $\mathrm{ml}$ of $1 \mathrm{mM} \mathrm{Ag}\left(\mathrm{NO}_{3}\right)_{2}$ solution by drop wise at $60-80^{\circ} \mathrm{C}$ for 1 hour with the help of magnetic stirrer. The contents were centrifuged at $10,000 \mathrm{rpm}$ for 20 minutes to avoid the presence of any biological impurities and it is used for further characterization and antimicrobial studies.

\section{Characterization of SNPs}

The reaction mixture was subjected to analyze by UVVIS absorption spectra using a Spectro UV 2080 Double beam $1200 \mathrm{~L} / \mathrm{mm}$ spectrophotometer, Analytical technologies, India for preliminary conformation of synthesized nanoparticles are SNPs. Fourier Transform Infra-Red (FT-IR) spectra of synthesized SNPs was analysed in the range of $4,000 \mathrm{~cm}^{-1}$ to $500 \mathrm{~cm}^{-1}$ with an ALPHA interferometer (ECO-ATR), Bruker, Ettlingen, Karlsruhe, Germany by $\mathrm{KBr}$ pellet method to know the possible biomolecules responsible for reduction and stabilization of SNPs. Xray diffraction of synthesized nanoparticles were examined by using an X-Ray Diffractometer (XRD) (Shimadzu, XRD-6000) equipped with $\mathrm{Cu} \mathrm{K} \alpha$ radiation source using $\mathrm{Ni}$ as filter at a setting of $30 \mathrm{kV} / 30 \mathrm{~mA}$ to know the crystalline nature of SNPs. Purity of SNPs was analyzed by using FEI Quanta 200 FEG HR-SEM machine equipped with EDAX instrument. To know the size, shape, agglomeration pattern and dispersed nature of nanoparticles was carried out by using Atomic Force Microscopy (AFM) by NOVA NT-MDT SOLVER NEXT, Russia. Scanning Electron Microscopy (SEM) by FEI Quanta 200 FEG HR-SEM machine. Transmission Electron Microscopy (TEM) by using HF3300 advanced 300kV TEM/STEM from Hitachi.

\section{Antimicrobial studies of SNPs}

The antimicrobial potency of green synthesized silver nanoparticles from leaf extract of $A$. digitata was analyzed against two Gram positive bacterial strains like Bacillus subtilis, Staphylococcus aureus and five Gram negative bacterial strains like Escherichia coli, Klebsiella pneumoniae, Proteus vulgaris, Pseudomonas aeruginosa and Salmonella typhimurium. Antifungal studies were carried out in five fungal strains like Alternaria solani, Aspergillus flavus, Aspergillus niger, Penicillium chrysogenum and Trichoderma harzianum procured from Dept. of Microbiology, Sri Venkateswara University, Tirupati. Disc diffusion method (Cruickshank, 1986) was followed for testing antimicrobial activity against green synthesized SNPs and comparative studies were made with plant leaf extract as a positive control, $1 \mathrm{mM} \mathrm{Ag}\left(\mathrm{NO}_{3}\right)_{2}$ as negative control and Streptomycin/Fluconazole as a standard. $7 \mathrm{~mm}$ sterile discs were prepared from whatman no.1 filter paper and $20 \mu \mathrm{l}$ of $50 \mu \mathrm{g} / \mathrm{ml}$ concentration of plant extract, SNPs, standards like Streptomycin/Fluconazole and $1 \mathrm{mM}$ concentration of $\mathrm{Ag}\left(\mathrm{NO}_{3}\right)_{2}$ solution are loaded on separate discs and allowed to air dry for one hour. Freshly prepared nutrient agar media for bacteria and potato dextrose agar media for fungi were poured into sterile petriplates, allowed for 30 minutes for solidification. The plates were swabbed with microbial cultures and placed the previously prepared discs and the experiment is carried out in triplicates. The plates were incubated at $37{ }^{\circ} \mathrm{C}$ for 24 to $48 \mathrm{~h}$ then the zone of inhibition was measured with the help of scale and tabulated the results.

\section{RESULTS AND DISCUSSION}

When the addition of $1 \mathrm{mM} \mathrm{Ag}\left(\mathrm{NO}_{3}\right)_{2}$ solution to leaf extract, the colour change from yellow to brown indicates the formation of nanoparticles. UV-VIS spectroscopy analysis of synthesized nanoparticles shows broad peak at $431 \mathrm{~nm}$ further confirms the synthesized nanoparticles are SNPs (Figure 1). Same type of results was observed in Ficus religiosa leaf extract mediated synthesis of SNPs (Antony et al., 2013). This broad peak obtained is due surface plasmon resonance of silver nanoparticles in the reaction mixture. Here the nanoparticles in reaction mixture absorbs light at different wavelengths and excited due to charge density at the interface between conductor and insulator of UVVIS spectroscope to give a respective peak, the mechanism known as surface plasmon resonance (SPR). 


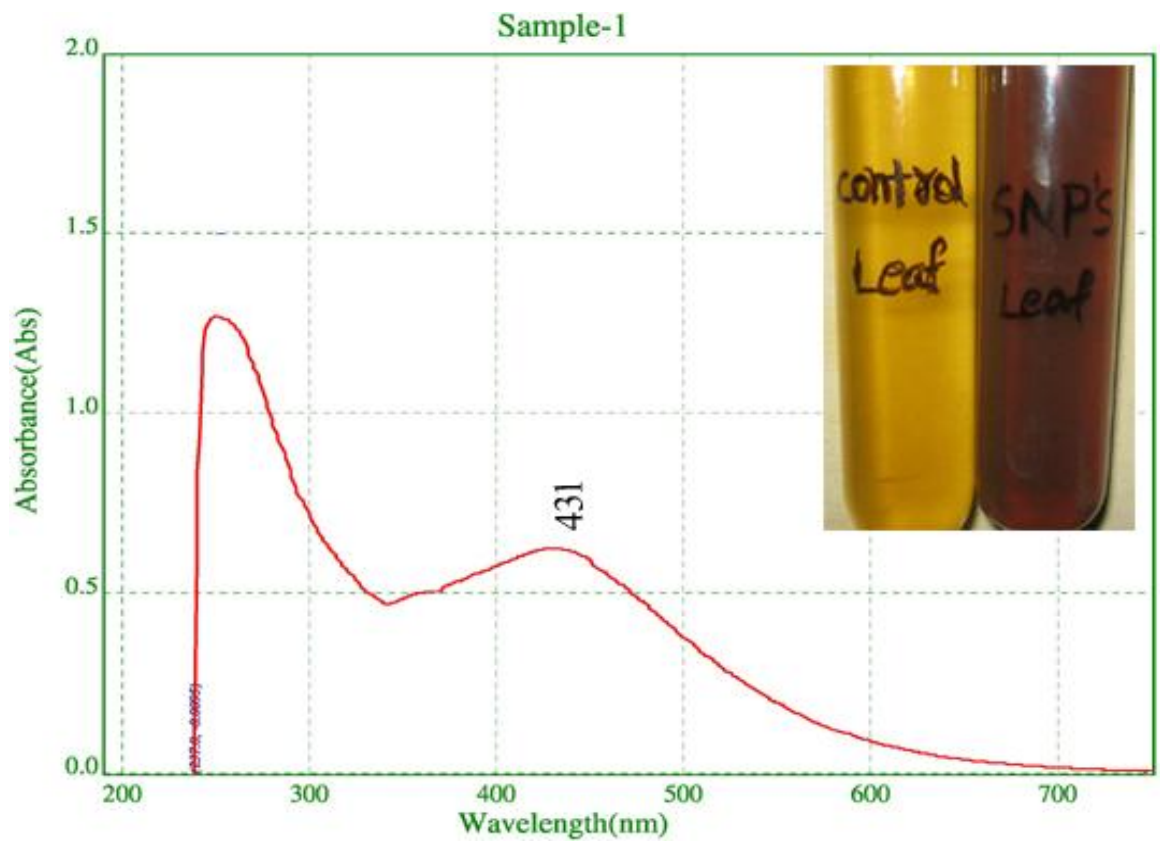

Fig. 1: Surface Plasmon Resonance analysis of green synthesized SNPs with UV-VIS spectroscopy shows broad peak at $431 \mathrm{~nm}$. Inset photograph shows colour change pattern from Yellow to Brown.

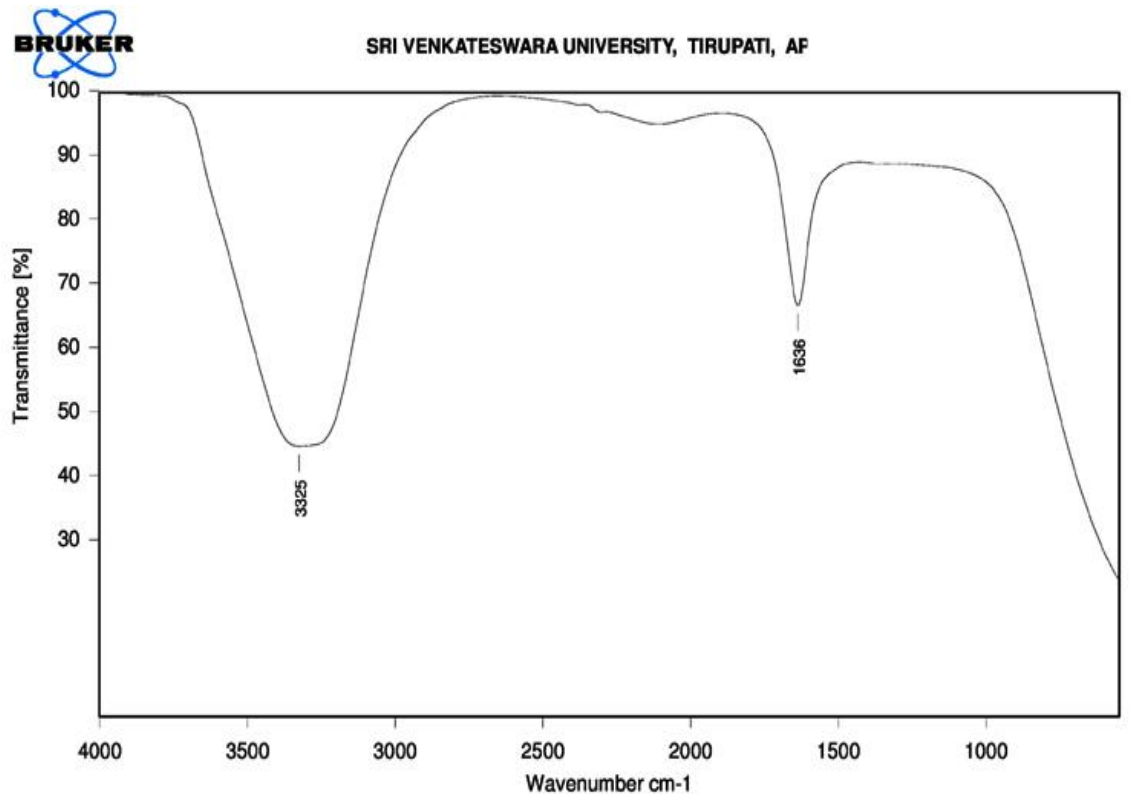

Fig. 2: FTIR spectroscopic studies of green synthesized SNPs shows broad peaks at $1636 \mathrm{~cm}^{-1}$ and $3325 \mathrm{~cm}^{-1}$

The wavelength of peak and the intensity of SPR depend on size, shape, aggregation pattern of particles and stabilizers present in the reaction medium (Gao et al., 2014). FTIR spectrum of synthesized SNPs shows broad peaks at $3325 \mathrm{~cm}^{-1}$ assigned for $\mathrm{O}-\mathrm{H}$ bond of phenols and $1636 \mathrm{~cm}^{-1}$ assigned for $\mathrm{N}-\mathrm{H}$ bond of primary amines (Figure 2).

This FTIR studies suggested that the hydroxyl groups of phenols and amide groups of proteins from plant extract forming a layer to the nanoparticles and acting as a capping agent to prevent agglomeration and providing stability to the medium. Same type of results was found in Myristica fragrans leaf extract mediated synthesis of silver nanoparticles (Sharma et al., 2014).
Crystallographic nature of the synthesized SNPs was analysed by using X-ray diffraction (XRD) analysis shows four intensive peaks at $38.1^{0}, 46.2^{0}, 64.5^{\circ}$ and $77.3^{\circ}$ of $2 \theta$ degrees of $X$ axis corresponds to $111,200,220$ and 311 bragg reflections of Yaxis (Figure 3).

These bragg reflections confirms the face centered cubic structure of SNPs and it is coincided with International Centre for Diffraction Data (No. 04-0783). The mean particle diameter of synthesized SNPs is $44 \mathrm{nms}$, calculated according to DebyeScherrer equation $(D=k \lambda / \beta \cos \theta)$. The Full Width at Half Maximum (FWHM) values i.e., $\mathrm{k}=0.44$ were derived from 38,46 , 64 and 77 bragg reflections of $\mathrm{X}$-axis. 


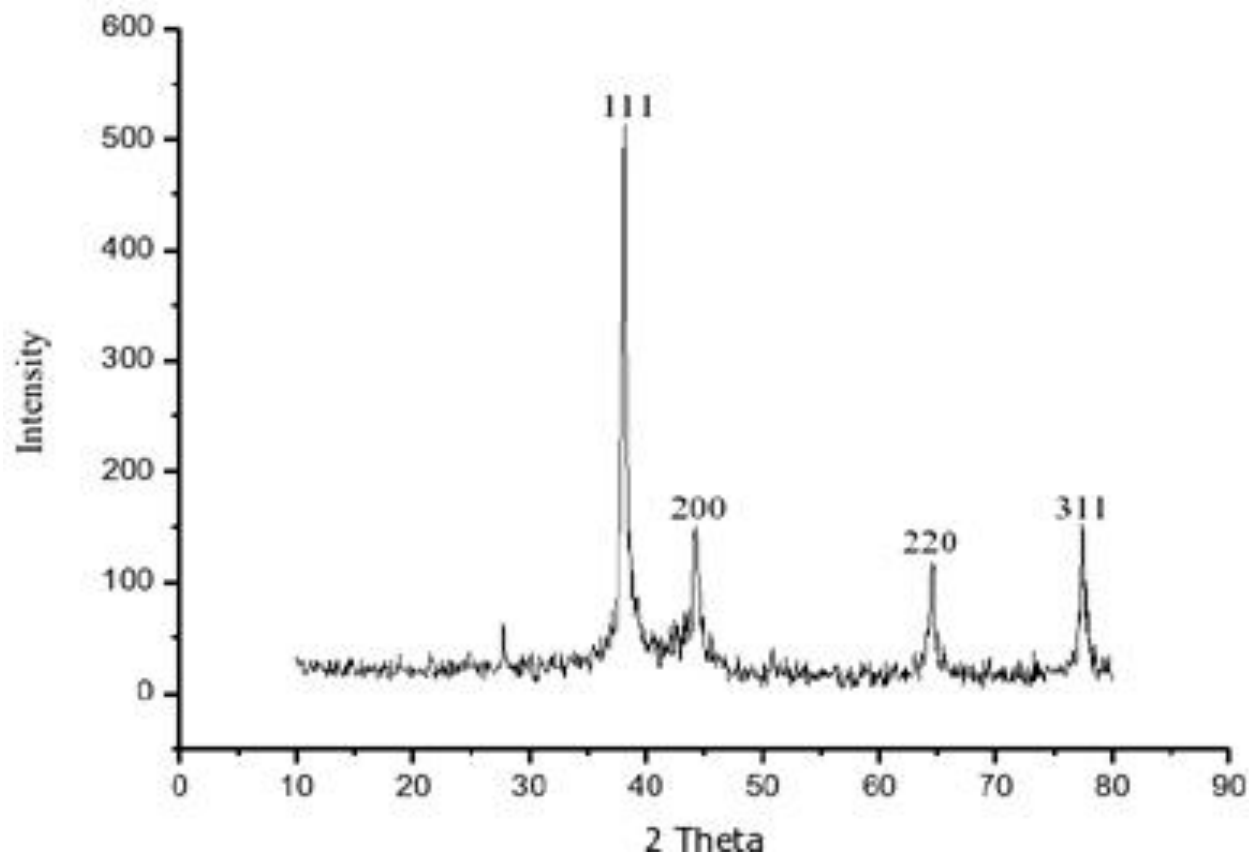

Fig. 3: XRD pattern of green synthesized SNPs from leaf extract of A. digitata shows different bragg reflections.
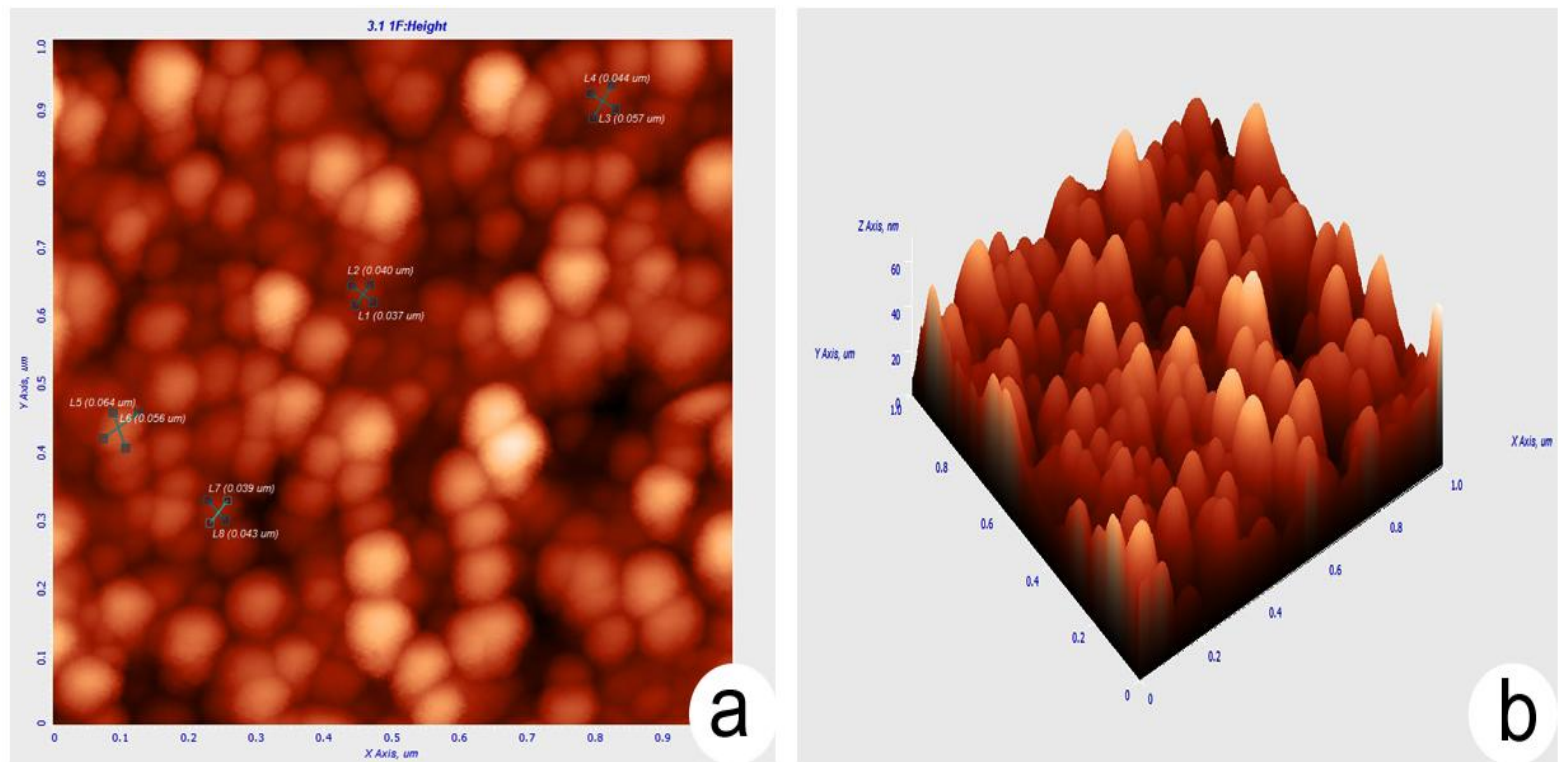

Fig.4: (a) $1 \mu \mathrm{m}$ resolution studies of green synthesized SNPs with AFM shows particles are spherical in shape, size range between 39 to $64 \mathrm{~nm}$ (b) 3D structures of SNPs analysed by NOVA-TX Software

AFM is a primary tool for characterizing topography of nanoparticles depositing thin films on glass slide. $1 \mu \mathrm{m}$ resolution studies with AFM reveals the particles are polydispersed, spherical in shape, having the size range from 39 to $64 \mathrm{~nm}$ (Figure 4a). Raw data obtained from AFM microscope is treated with specially designed image processing software (NOVA-TX) to further exploit the 3D image of the nanoparticle (Figure 4b). Better resolution studies with SEM with EDAX analysis provides further insight into the size, shape and percentage presence of nanoparticles in the reaction medium. $300 \mathrm{~nm}$ resolution studies with SEM analysis shows the SNPs are spherical in shape having size range from 12 to $14 \mathrm{~nm}$ (Figure 5a). EDAX analysis shows 34.22 weight percent of Ag metal along with $06.41 \%$ of Carbon, $02.42 \%$ of Nitrogen, $28.72 \%$ of Oxygen, $08.12 \%$ of Sodium, $02.41 \%$ of Magnesium, $01.05 \%$ of Aluminium, $02.29 \%$ of Silicon, $08.74 \%$ of Aurum and $05.62 \%$ of Calcium (Table 1). $34.22 \%$ of $\mathrm{Ag}$ metal in the sample indicates high purity of silver nanoparticles (Figure 5b). Crystalline nature of synthesized SNPs was analyzed by using selected area electron diffraction (SAED) by directing the electron beam perpendicular to nanoparticles. 
Table. 1: EDAX analysis of sample containing different metals .

\begin{tabular}{ccc}
\hline S. No & Element & Weight $(\%)$ \\
\hline 1. & $\mathrm{C}$ & 06.41 \\
2. & $\mathrm{~N}$ & 02.42 \\
3. & $\mathrm{O}$ & 28.72 \\
4. & $\mathrm{Na}$ & 08.12 \\
5. & $\mathrm{Mg}$ & 02.41 \\
6. & $\mathrm{Al}$ & 01.05 \\
7. & $\mathrm{Si}$ & 02.29 \\
8. & $\mathrm{Au}$ & 08.74 \\
9. & $\mathrm{Ag}$ & 34.22 \\
10. & $\mathrm{Ca}$ & 05.62 \\
\hline
\end{tabular}
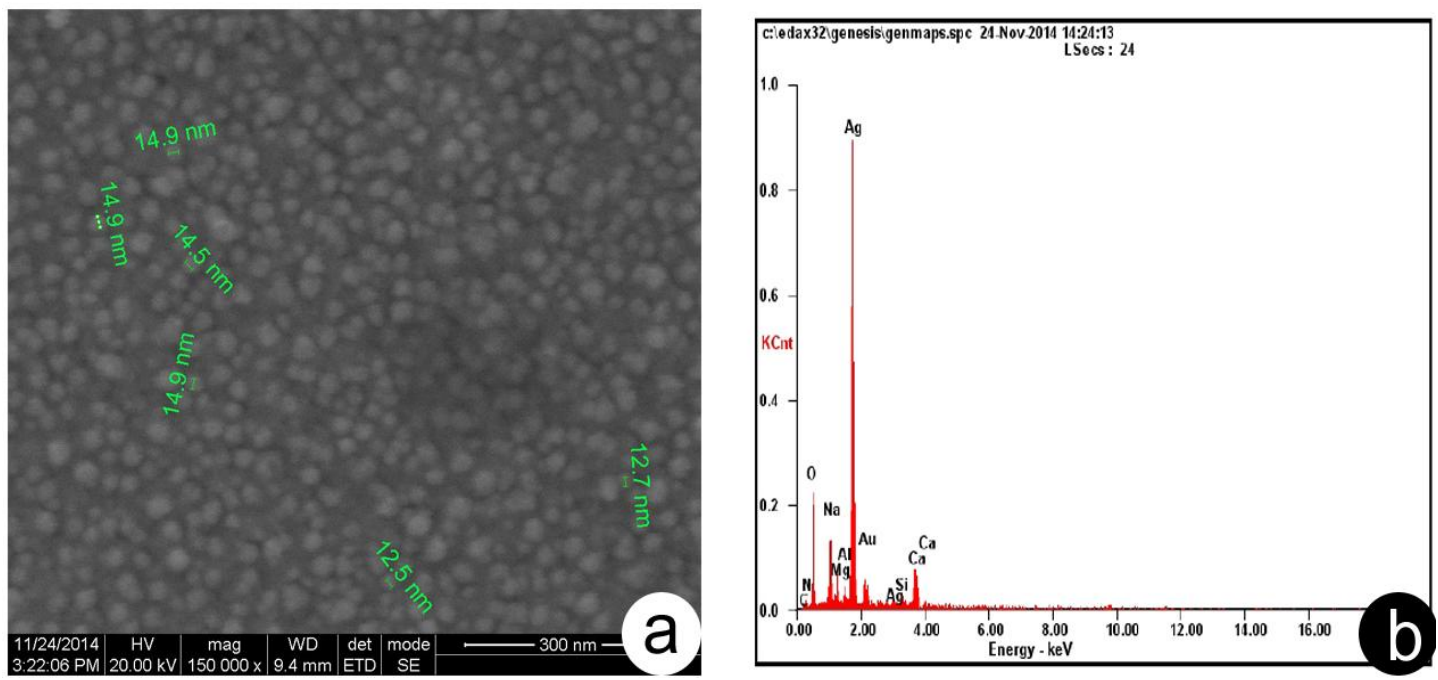

Fig.5: (a) $300 \mathrm{~nm}$ resolution studies of SNPs by SEM analysis shows the particles are spherical in shape, size range from 12 to $14 \mathrm{~nm}$ (b) EDAX analysis of synthesized SNPs shows 34.22 weight percent of Ag metal in the sample.
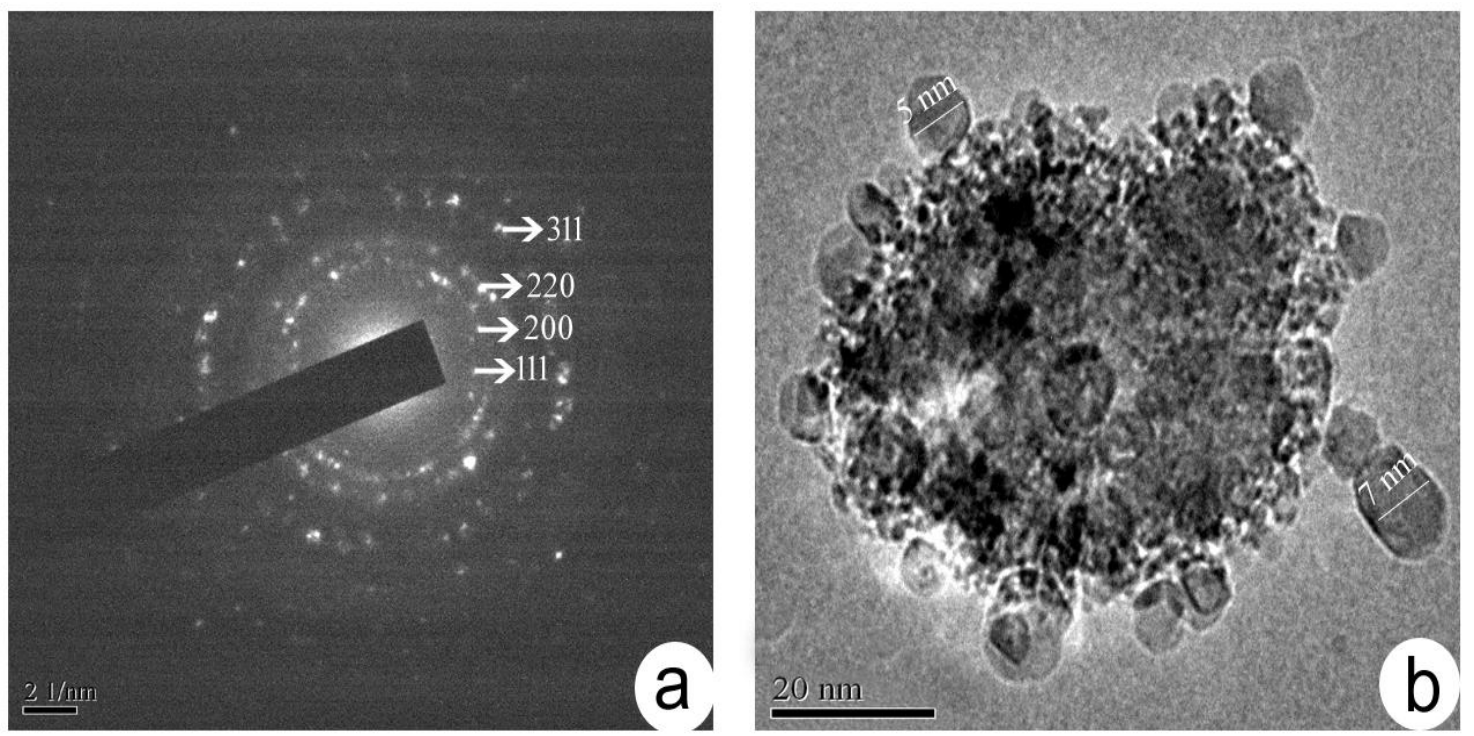

Fig.6: (a) SAED pattern of synthesized SNPs shows the particles are crystalline in nature (b) $20 \mathrm{~nm}$ resolution analysis of TEM micrographs shows 5 to $7 \mathrm{~nm}$ sized. snherical shaned nolvdisnersed narticles

The SAED pattern of fringe array of spots can be corresponds to 111, 200, 220 and 311 shows the crystallographic nature and face centred cubic structure of SNPs (Figure 6a).

The bragg reflections of XRD pattern is correlated with this SAED pattern of SNPs, clearly indicates the nanoparticles are crystalline in nature. Higher resolution studies with TEM analysis reveals size, shape and agglomeration pattern of nanoparticles. $20 \mathrm{~nm}$ resolution studies with TEM reveals the nanoparticles are spherical in shape and size range from 5-10 nm (Figure 6b). Antimicrobial activity of green synthesized SNPs from A. digitata leaf was evaluated against two Gram positive, five Gram negative bacterial and five fungal isolates. 
The highest zone of inhibition was observed in $E$. coli followed by $S$. typhimurium, $P$. vulgaris, $K$. pneumoniae, $P$. aeruginosa, B. subtilis and S. aureus. Whereas in the case of fungal pathogens the highest inhibitory zones was observed in $A$. flavus followed by T. harzianum, A. niger, P. chrysogenum and A. solani (Figure 7, Table 2, Graph 1). Bacterial pathogens are more susceptible and give highest zone of inhibition when compare to fungal pathogens treated with SNPs. It is due to bacterial cell walls are made up of peptidoglycons, but in the case of fungi the cell walls are made up of chitin (a type of polysaccharide contains nitrogen) having more complex structure, tough in nature, flexible and rigid than bacteria cell walls.

Due to this tough nature, penetration of nanoprticles is somewhat difficult between the barriers of cell walls in fungi. Among the bacterial pathogens Gram negative species are more susceptible and give highest zone of inhibition when compare to Gram positive species. It is due to, the Gram positive bacterial cell walls are made up of peptidoglycons (together with polypeptide contains proteins). This peptidoglycon materials are less in case of Gram negative bacteria. Small size, spherical shaped particles having high surface ratio to interact with cell walls of pathogens and gives better antimicrobial activity. 5 to 68 $\mathrm{nm}$ sized, spherical shaped SNPs synthesized from leaf extract of Syzygium alternifolium shows excellent antimicrobial potency on clinically isolated pathogens (Yugandhar and Savithramma, 2015). Leaf extract mediated synthesis of SNPs from Avicennia marina produce 71 to $110 \mathrm{~nm}$ sized, spherical shaped nanoparticles having potential antimicrobial activity (Gnanadesigan et al., 2012). Most of the scientists states that SNPs interact with cell membrane of bacteria (Sondi and Sondi, 2004) and fungi (Krishnaraj et al., 2012) causes structural changes and membrane integrity of pathogens leads to cell death. Some other states that SNPs interact with electron phosphorous and sulphur containing compounds such as DNA and Proteins, resulting in cell death (Baker et al., 2005). In our previous studies, synthesis of SNPs from A. digitata bark extract also shows excellent antimicrobial activity (Marutikasavakumar et al., 2015) against different microorganisms. Smaller particles have larger surface area available for interaction and will give more effect than the larger particles, present study also clearly reveals particle size range from 5 to $64 \mathrm{~nm}$ with spherical shape confirmed by AFM, SEM, TEM and prove its high potential antimicrobial activity.
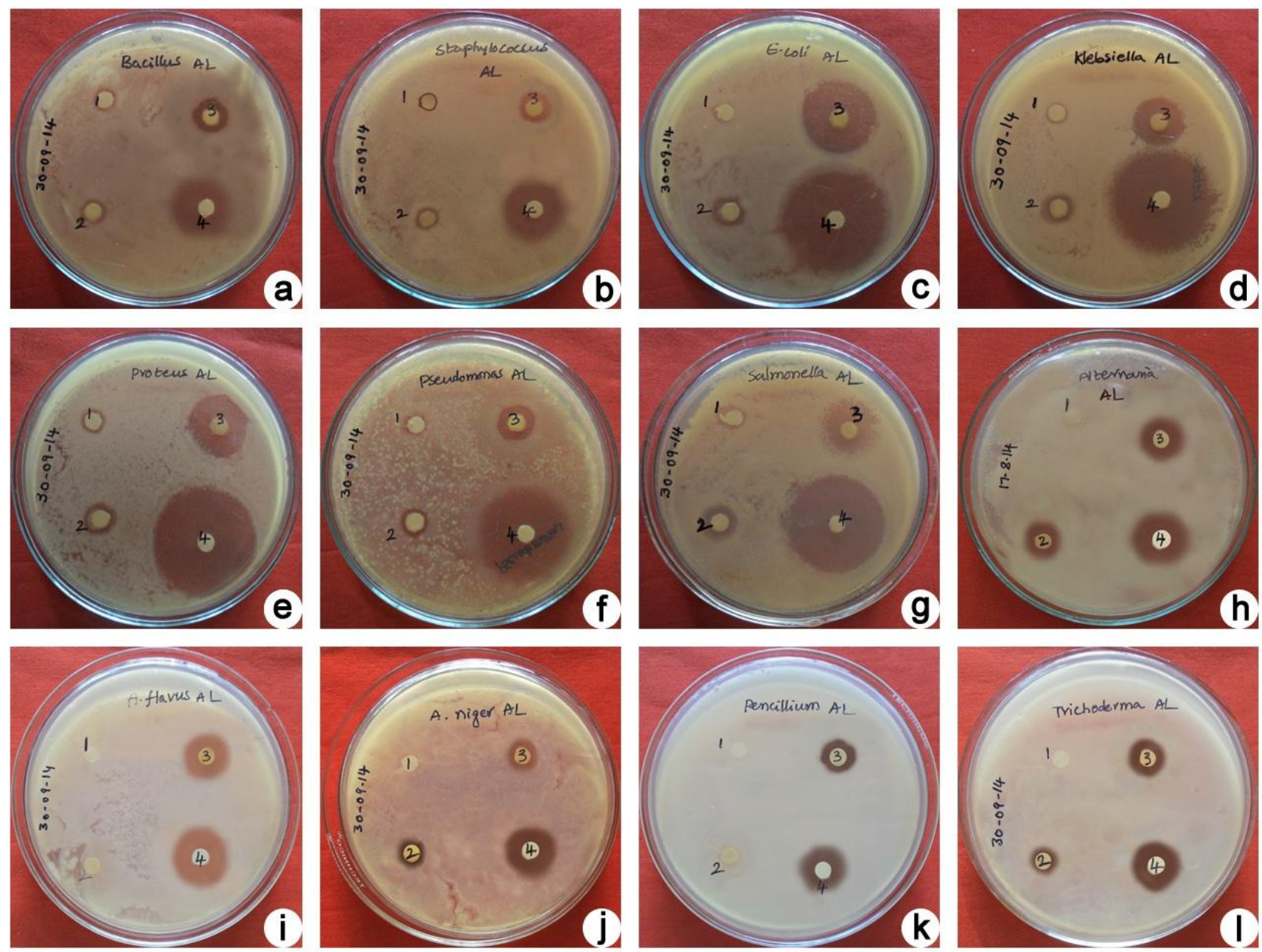

Fig.7: Antimicrobial studies of green synthesized SNPs from leaf extract of A. digitata (a) B. subtilis (b) S. aureus (c) E. coli (d) K. pneumoniae (e) P. vulgaris (f) P. aeruginosa (g) S. typhimurium (h) A. solani (i) A. flavus (j) A. niger (k) P. chrysogenum (l) T. harzianum

(1) Plant extract (2) $\mathrm{Ag}\left(\mathrm{NO}_{3}\right)_{2}$ (3) SNPs (4) Streptomycin/Fluconazole. 
Table 2: Results obtained from zone of inhibition of different extracts ( $\mathrm{mm}$ ).

\begin{tabular}{llcccc}
\hline S. No & Name of the organism & Plant extract & $\mathbf{A g}\left(\mathbf{N O} \mathbf{~}_{\mathbf{2}}\right.$ & SNPs & Streptomycin/Fluconazole \\
\hline 1. & B. subtilis & $7.3 \pm 0.10$ & $9.4 \pm 0.60$ & $12.5 \pm 0.81$ & $18.2 \pm 0.21$ \\
2. & S. aureus & $7.5 \pm 0.57$ & $9.0 \pm 0.91$ & $11.1 \pm 0.44$ & $17.5 \pm 0.51$ \\
3. & E. coli & $7.7 \pm 0.56$ & $10.2 \pm 0.48$ & $24.1 \pm 0.60$ & $28.8 \pm 0.41$ \\
4. & K. pneumoniae & $7.8 \pm 1.08$ & $10.6 \pm 0.32$ & $17.3 \pm 0.32$ & $28.2 \pm 0.10$ \\
5. & P. vulgaris & $7.4 \pm 0.17$ & $11.5 \pm 0.30$ & $20.0 \pm 1.19$ & $27.1 \pm 0.21$ \\
6. & P. aeruginosa & $7.8 \pm 0.83$ & $10.4 \pm 0.21$ & $13.2 \pm 0.52$ & $24.2 \pm 0.14$ \\
7. & S. typhimurium & $9.4 \pm 1.34$ & $11.5 \pm 0.21$ & $21.7 \pm 0.47$ & $26.2 \pm 0.14$ \\
8. & A. solani & 0 & $8.2 \pm 0.18$ & $10.4 \pm 0.32$ & $14.3 \pm 0.12$ \\
9. & A. flavus & 0 & 0 & $15.4 \pm 0.14$ & $18.2 \pm 0.17$ \\
10. & A. niger & 0 & $8.3 \pm 0.14$ & $11.4 \pm 0.28$ & $15.7 \pm 0.32$ \\
11. & P. chrysogenum & 0 & 0 & $10.5 \pm 0.14$ & $15.4 \pm 0.17$ \\
12. & T. harzianum & 0 & $9.3 \pm 0.10$ & $11.5 \pm 0.21$ & $16.5 \pm 0.07$ \\
\hline
\end{tabular}

Values are average of triplicates, '0'idicates no inhibition zone, ' \pm ' indicates Standard Error

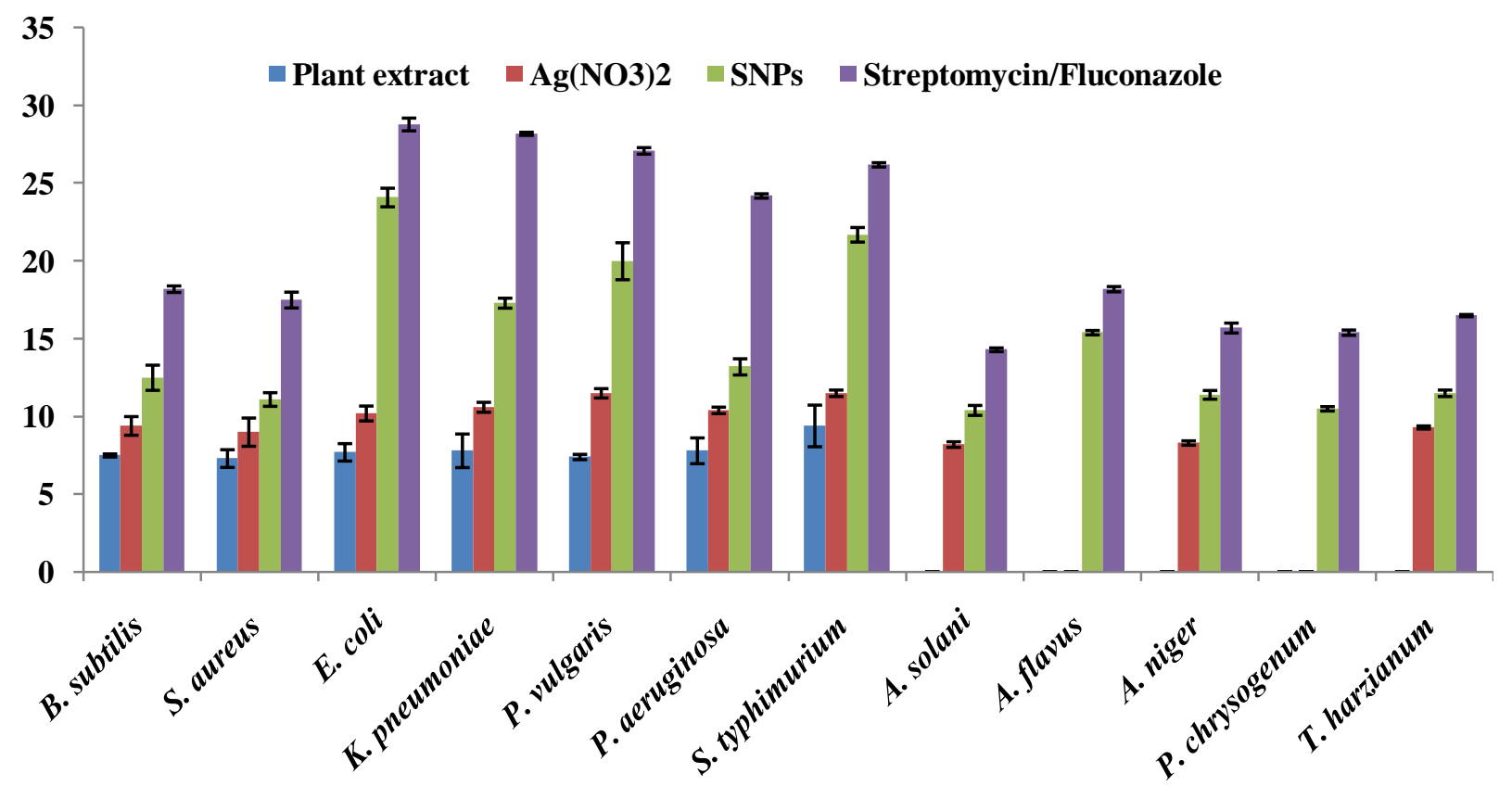

Graph. 1: Comparison of zone of inhibition of green synthesized SNPs with different extracts on clinically isolated different bacterial and fungal pathogens.

\section{CONCLUSION}

In the present study we develop a green method for synthesis of SNPs from leaf extract of $A$. digitata. In conventional method of chemical synthesis protocol uses toxic chemicals like Sodium borohydride (NaBH4) and Citrate as reducing agents. Topical exposure of $\mathrm{NaBH} 4$ severely irritate skin and eye, breathing $\mathrm{NaBH}_{4}$ irritate nose and throat, higher exposures can cause pulmonary edema, very higher exposure may affect nervous system. Citrate causes hypocalcaemia, fatigue, paresthesia and muscle spasms. Conventional Physical approaches use laser ablation and evaporation/condensation method, which faces some disadvantages like, it occupies large space, consumes a greater amount of power energy and these are not cost effective. Most of the scientists proved to use of plant extracts as effective reducing agents for synthesis of eco-freindly, cost effective SNPs. In the present study we proved $A$. digitata leaf extract also acts as an effective reducing agent for production of high amount of narrow range silver nanoparticles and as eco-friendly antimicrobial agents.

\section{ACKNOWLEDGEMENTS}

The authors are highly thankful to DST-SERB for financial assistance. DST-PURSE, Sri Venkateswara UniversityTirupati, JNTU-Hyderabad and IIT-Madras, Chennai for providing characterization facilities.

\section{REFERENCES}

Herrera-Becerra R, Zorrilla C, Rius JL, Ascencio JA. Electron microscopy characterization of biosynthesized iron oxide nanoparticles. Appl Phys A: Mater Sci Process, 2008; 9:241- 246.

Lee HJ, Song JY, Kim BS. Biological synthesis of copper nanoparticles using Magnolia kobus leaf extract and their antibacterial activity. J Chem Technol Biotechnol, 2013; 88:1971-1977.

Yugandhar P, Savithramma N. Green synthesis of calcium carbonate nanoparticles and their effects on seed germination and seedling growth of Vigna mungo (L.). Hepper. Int J Adv Res, 2013; 1:89-103.

Veronica A, Isaac H, Jose RPV, Miguel JY, Horacio T, Patricia S, Jorge LGT. Size controlled gold nanoparticle formation by Avena sativa biomass: use of plants in nanobiotechnology. J Nanopart Res, 2014; 6:377382. 
Bhumi G, Savithramma N. Biological Synthesis of zinc oxide nanoparticles from Catharanthus roseus (L.) G. Don. leaf extract and validation for antibacterial activity. Int J Drug Dev Res, 2014; 6:208-214.

Yugandhar P, Savithramma N. Biosynthesis, characterization and antimicrobial studies of green synthesized silver nanoparticles from fruit extract of Syzygium alternifolium (Wt.) Walp. an endemic, endangered medicinal tree taxon. Appl Nanosci, 2015. doi: 10.1007/s13204-015-0428-4.

Morones JR, Elechiguerra JL, Camacho A, Holt K, Kouri JB, Ramirez JT, Yacaman MJ. The bactericidal effect of silver nanoparticles. Nanotechnology, 2005; 16:2346-2353.

Veerasamy R, Xin TZ, Gunasagaran S, Xiang TFW, Yang EFC, Jeyakumar N, Dhanaraj SA. Biosynthesis of silver nanoparticles using mangosteen leaf extract and evaluation of their antimicrobial activities. J Saudi Chem Soc, 2011; 15:113-120.

Anamika M, Sanjukta C, Prashant MR, Geeta W. Evidence based green synthesis of nanoparticles. Adv Mater Lett, 2012; 3:519-525.

Wickens GE. 2008. The Baobabs: Pachycauls of Africa, Madagascar and Australia. Springer publishers, Netharlands.

Wickens GE. 1979. The uses of the baobab (Adansonia digitata $L$.) in Africa. In: Kunkel G, ed. Taxonomic aspects of African economic botany. Las Palmas, Grand Canaria.

Vermaak I, Kamatou GPP, Komane-Mofokeng B, Viljoen AM, Beckett K. African seed oils of commercial importance-Cosmetic applications. S Afr J Bot, 2011; 77:920-933.

Qarawi, AAA, Al-Damegh MA, El-Mougy SA Hepatoprotective Influence of Adansonia digitata pulp. J Herbs Spices Med Plants, 2003; 10:1-6.

Sibibe M, Williams JT. 2002. Baobab- Adansonia digitata. Fruits for the future 4, International Centre for Underutilised Crops, Southampton, UK, p 96.

Sulaiman LK, Oladele OA, Shittu IA, Emikpe BO, Oladokun AT, Meseko CA. In-ovo evaluation of the antiviral activity of methanolic root-bark extract of the African Baobab (Adansonia digitata Lin), Afr J Biotechnol, 2011; 10:4256-4258.

Krishnappa K, Elumalai K, Dhanasekaran S, Gokulakrishnan J. Larvicidal and repellent properties of Adansonia digitata against medically important human malarial vector mosquito Anopheles stephensi (Diptera: Culicidae). J Vector Borne Dis, 2012; 49:86-90.

Oloyede GK, Onocha PA, Soyinka J, Oguntokun OW, Thonda E. Phytochemical screening, antimicrobial and antioxidant activities of four Nigerian medicinal plants. Ann Biol Res, 2010; 1:114-120.

Gwarzo MY, Bako HY. Hypoglycemic activity of methanolic fruit pulp extract of Adansonia digitata on blood glucose levels of alloxan induced diabetic rats. Int J Anim Vet Adv, 2013; 5:108-113,

Musila MF, Dosasaji SF, Nguta JM, Lukhoba CW, Munyao JM. In vivo antimalarial activity, toxicity and phytochemical screening of selected antimalarial plants. J Ethnopharm, 2013; 146:557-561
Singh S, Parasharami V, Rai S. Medicinal uses of Adansonia digitata L.: an endangered tree species. J Pharm Sci Innovation, 2013; 2:14-16.

Marutikesavakumar Ch, Yugandhar $\mathrm{P}$, Suhrulatha D, Savithramma N. Synthesis, characterization and antimicrobial studies of stem bark mediated synthesis of silver nanoparticles from Adansonia digitata (L.). J Pharm Sci Res, 2015; 7:76-82.

Cruickshank R. 1986. Medical microbiology: a guide to diagnosis and control of infection. Livingston publishers, Edinburgh.

Antony JJ, Sithika MAA, Joseph TA, Suriyakalaa U, Sankarganesh A, Siva D, Kalaiselvi S, Achiraman S. In vivo antitumor activity of biosynthesized silver nanoparticles using Ficus religiosa as a nanofactory in DAL induced mice model. Colloids Surf B, 2013; 108:185190.

Gao Y, Huang Q, Su Q, Liu R. Green Synthesis of silver nanoparticles at room temperature using kiwifruit juice. Spectrose Lett, 2014; 47:790-795.

Sharma G, Sharma AR, Kurian M, Bhavesh R, Nam JS, Lee SS. Green synthesis of silver nanoparticle using Myristica fragrans (nutmeg) seed extract and its biological activity. Digest Journal of Nanomaterials and Biostructures, 2014; 9:325-332.

Yugandhar P, Savithramma N. Leaf assisted green synthesis of silver nanoparticles from Syzygium alternifolium (Wt.) Walp. characterization and antimicrobial studies. Nano Biomed Eng, 2015; 7:29 37. doi: 10.5101/nbe.v7i2.p29-37.

Gnanadesigan M, Anand M, Ravikumar S, Maruthupandy M, Syed Ali M, Vijayakumar V, Kumaraguru AK. Antibacterial potential of biosynthesised silver nanoparticles using Avicennia marina mangrove plant. Appl Nanosci, 2012; 2:143-147.

Sondi I, Sondi BS. Silver nanoparticles as antimicrobial agent: a case study on E. coli as a model for Gram-negative bacteria. J Colloid Interface Sci, 2004; 275:177-182.

Krishnaraj C, Ramachandran R, Mohan K, Kalaichelvan PT. Optimization for rapid synthesis of silver nanoparticles and its effect on phytopathogenic fungi. Spectrochim Acta Part A, 2012; 93:9599

Baker C, Pradhan A, Pakstis L, Pochan DJ, Shah SI. Synthesis and antibacterial properties of silver nanoparticles. J Nanosci Nanotechnol, 2005; 5:24-29.

\section{How to cite this article:}

Chennareddy MKK, Yugandhar $\mathrm{P}$ and Nataru S. Adansonia digitata leaf extract mediated synthesis of silver nanoparticles; characterization and antimicrobial studies. J App Pharm Sci, 2015; 5 (08): 082-089. 